\title{
Using Case Studies to Develop Theory: Roadmap to a Dialogue
}

\author{
DANIEL B. FISHMAN ${ }^{\text {a,b }}$ \\ ${ }^{\mathrm{a}}$ Graduate School of Applied and Professional Psychology, Rutgers University, Piscataway, NJ \\ ${ }^{\mathrm{b}}$ Correspondence concerning this article should be addressed to Daniel B. Fishman, Graduate School of Applied \\ and Professional Psychology, Rutgers University, 152 Frelinghuysen Road, Piscataway, NJ 08854, USA. \\ E-mail: dfish96198@aol.com
}

\begin{abstract}
This issue's target article by William Stiles (2009) presents a general paradigm that explains how the logical operations of deduction, induction, and abduction can be applied to case-study-level observations in order to build, test, and refine applied psychology theories in areas like psychotherapy. Stiles' paradigm is exemplified in the development of his own assimilation model of psychological change across many types of successful therapy. The subsequent commentaries, written by nine well-known psychologists representing a wide diversity of perspectives and expertise, fall into three general categories. These include illustrations of the usefulness of Stiles paradigm, and critiques of the Stiles paradigm as either being insufficiently grounded in mainstream scientific method and philosophy of science, or being too grounded in traditional science and not open to new philosophical developments in the areas of moral theory, pragmatic approaches to truth, and methodical hermeneutics. Because of the richness of the issues raised here, publication of further dialogue between Stiles and the commentators is planned for 2010.
\end{abstract}

Key words: logical operations; case studies; theory-building; assimilation model; deduction; induction; abduction; conflict resolution; forensic assessment; interpersonal defense; non-abstractionist theory; philosophy of science; Freudian case studies; randomized clinical trials; moral theory; pragmatism; methodical hermeneutics

Systematic case studies are a research method that can be employed for a variety of purposes. The case studies published in the PCSP journal are each grounded in a particular guiding conception, that is, a particular theoretical model, and each study spells out the ways in which that conception plays out in an individual case.

In the present case method issue, the focus is on the use of systematic, qualitative case studies in developing and refining theory. This is in contrast to the typical way theory is developed and refined in scientific psychology, namely, through experimental and quantitative group studies. Specifically, William Stiles (2009) develops a general paradigm that explains how the logical operations of deduction, induction, and abduction can be applied to case-study-level observations in order to build, test, and refine applied psychology theories in areas like psychotherapy. In this effort, deduction focuses on logical consistency and interconnection 
among a theory's parts, induction involves applying observations to theory, and abduction involves creating, refining, and elaborating theory.

Stiles’ paradigm rests on certain epistemological assumptions about the philosophy of knowledge and upon a particular methodology for developing theory.

Stiles’ paradigm is in part drawn from his experience in building a theory of psychological change that he and his colleagues have called the assimilation model (Stiles et al., 1990; 2002; 2003) This model is a developmental account of therapeutic change that describes a regular sequence of stages through which a client's experience of his or her problems pass in successful psychotherapy, along with processes that underlie it. A core strategy in this work has been tracking a client's talking about their problems across psychotherapy sessions in intensive case studies, and then gradually elaborating a theoretical description of the observed changes in how the client experiences and cognitively and emotionally processes these topics. At my request, in Appendix A of Stiles' present (2009) article, there is included an earlier published description (Stiles, 2003) of some of the details of using case studies to develop the assimilation model. Also included in Appendix A is a description of how Stiles' paradigm of case-based theory building is illustrated in the well-known clinical case studies of Sigmund Freud.

Stiles’ (2009) article, including Appendix A, is discussed by nine commentators, all of whom are well-known scholars and researchers. These authors were selected to represent a wide diversity of perspectives and expertise. Because of the richness of the dialogue in this present PCSP issue, the dialogue between Stiles and the commentators will have a second round, to be published in 2010. In this second round, Stiles will respond to the nine commentaries, then the commentators will have an opportunity to reply to Stiles, and finally Stiles will have an opportunity for a concluding response.

In the present issue, all nine commentators applaud Stiles' effort to develop a formal conceptual framework for using case studies to develop scientific theories and endorse the need for such a process. However, the nine differ in terms of what aspect of Stiles' paradigm they emphasize and the extent to which, overall, they are critical of the substance of the paradigm itself. Specifically, the first four commentators focus on illustrating the persuasiveness and usefulness of Stiles' paradigm by describing how it helps to explain what they do in their own, case-based professional work; and the last five take a more critical look at Stiles' paradigm from methodological and philosophical perspectives. Below is a roadmap for navigating these commentaries.

\section{Illustrations of the Usefulness of Stiles Paradigm}

\section{$\underline{\text { Kressel on Conflict Mediation }}$}

Kenneth Kressel (2009) describes the value of Stiles’ paradigm in helping to explain the case-study-based process he and his colleagues have gone through over a number of years to develop a theory of expert mediation practice, an area closely allied with psychotherapy. Kressel's work is based on case studies in three domains: divorce mediation in a family court; the management of conflict in a university medical center; and the mediation of conflict among 
scientists by ombudsmen-mediators at The National Institutes of Health. Kressel describes and explores three ways in which Stiles' (2009) argument for the case study as a theory building device resonates most strongly with his own experience in discovering:

the value of the case study for connecting theory to practice; the capacity of the case study to capitalize on problematic or unique experiences; and the ability of case studies to generate the kind of "rich observations" that allow theories to be productively modified and adapted (Kressel, 2009, p. 26).

While Kressel endorses Stiles' argument about the value of case study research enthusiastically as it applies to Kressel's own investigations in the domain of conflict mediation, he also discusses the need to deal with the problem of researcher bias by engaging other methods that are either more rigorous or that make use of alternative means of capturing the basic units of the theory being developed.

\section{Goodman-Delahunty and Foote on Forensic Evaluations of the Causation of Harm}

Jane Goodman-Delahunty and William Foote (2009) apply Stiles’ paradigm to develop a theory of causation of psychological injuries within a particular forensic case. The specific example considered is that of sexual harassment in the workplace by a particular complainant/plaintiff. This is a case-based context in which the dimensions of the case study are framed by the referral questions of the retaining counsel and by the law in that jurisdiction. Forensic evaluators in sexual harassment and other workplace discrimination cases typically use a three-stage model —assessing the status of the sexual harassment plaintiff before the alleged harassment, during those events, and following harassment incidents-to develop a theory relevant to a particular complainant for determining legal causation. This theory of legal causation distinguishes a complainant's symptoms and problems that were caused by the defendant versus by independent life events. Using Stiles' formulation, Goodman-Delahunty and Foote show how their three-stage model demonstrates Stiles' use of deductive, inductive and abductive logic in the evaluation process to more effectively build and test theories relevant to the forensic issues.

Westerman on the Processes of "Interpersonal Defense” in Psychotherapy

Michael Westerman (2009) applies Stiles’ paradigm to Westerman's own research area of developing a theory of interpersonal defense in psychotherapy. By "interpersonal defense" Westerman refers to phenomena that appear as discourse breaches in the flow of conversation between patient and therapist. These breaches occur when a patient tries to pursue an interpersonal wish in the patient-therapist relationship (e.g., for the therapist to treat the patient as ok and to empathically understand the patient when the patient shows or expresses him- or herself) while also trying to avoid feared interpersonal outcomes that might occur from pursuing the wish (e.g., the therapist might ignore or neglect the patient when the patient shows or expresses him- or herself). According to Westerman's theory, defensive interpersonal behavior leads to a complicated set of outcomes that serve to maintain it, even though defensive behavior patterns do not really lead to successful resolutions of wish-fear conflicts. Westerman describes how his research in this area, which began with observational and experimental group research 
designs, has been richly complemented by employing the type of case-study research designs presented by Stiles. In particular, Westerman presents material from a case he has studied to illustrate one of Stiles' main claims about how case studies can contribute to theory justification, namely, case studies are well-suited to evaluating theories because they provide opportunities to simultaneously compare observations to the multiple tenets of a theory. Westerman concludes by pointing out that case-based and group-based research methods each have offsetting pros and cons, strengthening the argument to use them both in a careful, considered manner. ${ }^{1}$

\section{Yanchar on the Advantage of Case-Based Research for Non-Abstractionist Theorizing}

Stephen Yanchar (2009) focuses on one of the general advantages of case-based, nonabstractionist theorizing: its capacity to break down the barrier between formal theory and its application to solve real-world problems. In his words:

it is widely acknowledged across disciplines that formal theory and everyday practice often fail to connect meaningfully with one another and that, in a sense, practice in actual work settings has tended to expand and evolve in ways that theory has not. . . . Cases provide the richness and contextual detail needed to inform theories that can, in turn, offer practitioners a glimpse into phenomena from a human standpoint. (pp. 73, 77).

Yanchar illustrates this idea with Malcolm Westcott's research regarding the experience of human freedom, an area where "the idea of invoking abstractions to explain human activity undermines any serious effort to consider persons as genuinely agentive beings” (p. 75).

\section{Critiques of the Stiles Paradigm as Not Connecting Clearly Enough to Traditional Science}

Nathan on the Methodological Limitations of Case-Based Theory Building and the Need to Complement Cases with Randomized Clinical Trials

Peter Nathan (2009) embraces Stiles' effort to enhance the reliability, rigor, and utility of theory-building case studies. However, Nathan expresses three major concerns about Stiles' arguments. First, Nathan disagrees with Stiles’ implication that in assessing psychotherapy theory, one has to make a choice between the case study approach and the group experimental method. In Nathan's view, both methods are essential for this purpose.

Second, Nathan disagrees with what he views as Stiles' apparent conviction that any theorist can use "logical operations" to test the validity of his or her theories.

When theorists have a substantial stake in a theory, it is not surprising that they emphasize observations, including those from case studies, which lend support to their theory and neglect or deny those that do not. ... In other words, Stiles' logical operations, which I

\footnotetext{
${ }^{1}$ Westerman also offers a nuanced critique of Stiles' views on context sensitivity, according to which case studies are context-sensitive and hypothesis-testing investigations are not. Westerman rejects that contrast by arguing that some hypothesis-testing studies are sensitive to context, but goes on to identify specific ways in which theorybuilding case studies are better than hypothesis-testing investigations with respect to context sensitivity.
} 
believe are powerful, are nonetheless at the mercy of human nature: Will theory-building clinicians use them as prescribed to test their theories and take the chance that they will reveal serious flaws in them? (p. 87)

Third, extending this second concern to Freud's classic case studies, Nathan specifically disagrees with Stiles' contention that Freud's case studies, and the many others modeled after them, qualify as scientific research.

\section{Held on the Need for Clearer Explication of Philosophy of Science Concepts}

Barbara Held (2009) analyzes Stiles’ paradigm in terms of established philosophy of science considerations, including

(a) the distinction between description and explanation in theory building, (b) the distinction between theory building and theory justification, and (c) the distinction between nomothetic and idiographic approaches to theory building in case-study methodology. (p. 90)

Held argues, based on a close reading and detailed analysis of Stiles' article, that in developing his framework, Stiles should explicate the conceptual and philosophical underpinnings of his paradigm. Held explores ways in which such explication can be accomplished and discusses its implications. For example, she requests clarification of Stiles' use of the terms "theoretical description" (p. 10) and "theoretical explanation" (p. 14), and she explores what she characterizes as seemingly anti-objectivist assumptions in Stiles' epistemology. These assumptions are reflected in Stiles' claim that "our experience of the world is ... as much a product of our own biological, psychological, and cultural makeup as of the objects and events that impinge on us” (p. 17), which could suggest that reality is not discovered but rather is "to some nontrivial extent constructed or created by us" (Held, 2009, p. 95). This raises the classic problem of relativism, because if our theories nontrivially color the nature of the reality we observe,

our observations would then be so significantly "permeated” by theory (among other factors) that there could never be sufficient independence between them to allow a fair/unbiased/objective test or evaluation of the theory (Held, 2009, p. 95).

\section{Critiques of the Stiles Paradigm as Being Too Grounded in Traditional Science}

\section{Miller on the Need to Integrate the Stiles Paradigm with Moral Theory}

Ronald B. Miller (2009) congratulates Stiles on developing "the surprising logical parallels between the way a case study and experimental data test a scientific theory in the field of psychotherapy," and on demonstrating that "careful attention to the tenets of logical positivist and neo-positivist philosophy of science requires such a conclusion” (p. 101). On the other hand, from his perspective on the philosophical assumptions of psychology and psychotherapy, Miller points out that Stiles’ arguments commit him to view theories of psychotherapy as essentially scientific theories, like those in the physical sciences. Based on his own work, Miller argues that this creates a problem for Stiles' paradigm because psychotherapy theories instead are fundamentally moral theories, that is: 
Theories of psychotherapy are ultimately theories of how to be helpful to people who are suffering from the pain of being human. This requires theories of the origin and meaning of that pain, how it is communicated in direct and indirect ways, and how it can be understood and transformed in the process of forming relationships with other people. All of this happens within the context of the effort of human beings to make the most of their lives under the often difficult circumstances in which we find ourselves. (Miller, 2009, p. 104)

Slife and Richardson on the Need to Conceptualize the Stiles Paradigm Within a Pragmatic Rather Than a Correspondence Theory of Truth

Brent Slife and Mike Richardson (2009) focus on one of the underlying aspects of Stiles' paradigm: his commitment to a correspondence theory of truth. This, in turn, commits Stiles to a dualist ontology that posits two fundamental realities in the world: experiences, such as thought, emotion, and interpretation, which are considered internal and "subjective"; and the material, "objective" world, which is considered external and independent of the mind. Slife and Richardson lay out a variety of ways that this dualist assumption creates difficulties about obtaining valid psychotherapy knowledge. For example, the separation of internal reality and external reality allows for a suspicion that the "subjective" values, meaning, and experience of the "internal reality" can get in the way of what is considered valid knowledge of the "external reality.” Yet values, meaning, and experience are crucial to what psychotherapy is all about.

As an alternative to Stiles' dualist assumption, Slife and Richardson present a nondualist alternative - the Consumer Reports' car ratings program-in which subjective values like reliability, drivability, owner satisfaction, and safety are an intrinsic part of the program. They then apply the lessons of this nondualist alternative to the case study and theory-building issues of psychology. Slife and Richardson also acknowledge that all epistemologies and methods have their own advantages and disadvantages, and they conclude that a pluralism of methods and epistemologies may be generally required, given the variety of research investigations attempted in the discipline.

\section{$\underline{\text { Rennie on the Stiles Paradigm as Hermeneutical }}$}

In a 2006 article, Stiles differentiates more traditionally scientific, theory-building research - the focus of Stiles' (2009) logical operations paradigm—and enriching research:

Theory-building research aims for an internally consistent, explicit understanding ... [yielding] improvement to the precision, generality, or realism of the theory . . .

Enriching research aims for a deeper, broader, more profound appreciation of the object of study. It systematically explores multiple perspectives and alternative interpretations, unpacking the historical and possible meanings of texts and events. The product of enriching research is not a unified theory but a richer or deeper appreciation by people, including researchers, participants, and readers (Stiles, 2006, p. 253).

Keeping in mind the distinction between theory-building and enriching research, Rennie (2009) argues that both the building of the assimilation model and the application of case studies to it can be seen as a matter of hermeneutics, or the interpretation of text. He holds that the 
model-building by Stiles and associates originally came out of a general hermeneutic analysis of extant theories. Alternatively, Rennie sees their application of case studies to the model as tacitly exemplifying his methodical form of hermeneutics. In this methodical form, he has adapted and incorporated C.S. Peirce's theory of inference involving the interplay of induction, abduction and deduction. This incorporation means that logical operations in Stiles' case study research indeed apply, but, Rennie maintains, more in terms of enriching research than theory-building research. In addition, in his commentary, Rennie discusses other aspects of the relationship between Stiles' enriching research and methodical hermeneutics.

\section{REFERENCES}

Goodman-Delahunty, J., \& Foote, W.E. (2009). Forensic evaluations advance scientific theory: Assessing causation of harm. Pragmatic Case Studies in Psychotherapy, Vol. 5(3), Article 4, 38-52. Available: http://hdl.rutgers.edu/1782.1/pcsp_journal

Held, B.S. (2009). The logic of case-study methodology. Pragmatic Case Studies in Psychotherapy, Vol. 5(3), Article 8, 90-100. Available: http://hdl.rutgers.edu/1782.1/pcsp_journal

Kressel, K. (2009). Lurching toward theory: The case of case study research in conflict mediation. Pragmatic Case Studies in Psychotherapy, Vol. 5(3), Article 3, 23-37. Available: http://hdl.rutgers.edu/1782.1/pcsp_journal

Miller, R.B. (2009). The logic of theory and the logic of practice. Pragmatic Case Studies in Psychotherapy, Vol. 5(3), Article 9, 101-107. Available: http://hdl.rutgers.edu/1782.1/pcsp_journal

Nathan, P.E. (2009). On systematizing theory-building case studies. Pragmatic Case Studies in Psychotherapy, Vol. 5(3), Article 7, 80-89. Available: http://hdl.rutgers.edu/1782.1/pcsp_journal

Rennie, D.L. (2009). Logic, hermeneutics, or both? Pragmatic Case Studies in Psychotherapy, Vol. 5(3), Article 11, 126-135. Available: http://hdl.rutgers.edu/1782.1/pcsp_journal

Slife, B.D., \& Richardson, M. (2009) Evaluating the philosophies of theory-building in case studies. Pragmatic Case Studies in Psychotherapy, Vol. 5(3), Article 10, 108-125. Available: http://hdl.rutgers.edu/1782.1/pcsp_journal

Stiles, W. B. (2002). Assimilation of problematic experiences. In J. C. Norcross (Ed.), Psychotherapy relationships that work: Therapist contributions and responsiveness to patients (pp. 357-365). New York: Oxford University Press.

Stiles, W. B. (2003). When is a case study scientific research? Psychotherapy Bulletin, 38, 6-11. [reprinted as Appendix A in Stiles, 2009].

Stiles, W. B. (2006). Numbers can be enriching. New Ideas in Psychology, 24, 252-262.

Stiles, W.B. (2009). Logical operations in theory-building case studies. Pragmatic Case Studies in Psychotherapy, Vol. 5(3), Article 2, 9-22. Available: http://hdl.rutgers.edu/1782.1/pcsp_journal

Stiles, W.B., Elliott, R., Llewelyn, S.P., Firth-Cozens, J.A., Margison, F.R., Shapiro, D.A., \& Hardy, G. (1990). Assimilation of problematic experiences of clients in psychotherapy. Psychotherapy, 27, 411-420. 
D.B. Fishman

Pragmatic Case Studies in Psychotherapy, http://pcsp.libraries.rutgers.edu

Volume 5, Module 3, Article 1, pp. 1-8, 9-12-09 [copyright by author]

Westerman, M.A. (2009). What can we learn from case studies? More than most psychologists realize. Pragmatic Case Studies in Psychotherapy, Vol. 5(3), Article 5, 53-70. Available: http://hdl.rutgers.edu/1782.1/pcsp_journal

Yanchar, S. (2009). Case studies and non-abstractionist theorizing. Pragmatic Case Studies in Psychotherapy, Vol. 5(3), Article 6, 71-79. Available:

http://hdl.rutgers.edu/1782.1/pcsp_journal 